\title{
TUMPANG SARI JAGUNG PADA PERKEBUNAN KELAPA SAWIT
}

\author{
*Wisnu Tri Wibowo \\ Fakultas Pertanian, Program Studi Agri Bisnis, Universitas Lancang Kuning \\ Pekanbaru.
}

Jln Yos Sudarso Kilometer 8 Rumbai, Pekanbaru - Riau

\begin{abstract}
ABSTRAK
Pembangunan pertanian bertujuan untuk meningkatkan ketahanan pangan, pendapatan petani dan sekaligus melestarikan lingkungan. Umumnya lahan di Riau berupa lahan kering yang memerlukan system pengelolaan yang tepat agar lebih berdaya guna. Dengan curah hujan sekitar 2000-3000 mm/tahun yang tersebar merata sepanjang tahun berpotensi besar untuk pengembangan komoditas kelapa sawit, yang diintegrasikan dengan tanaman pangan jagung, ubikayu dan lainnya, dengan pola tanam tumpangsari. Telaahan teknologi integrasi kelapa sawit dan tanaman pangan diarahkan untuk pengembangan teknologi usahatani yang produktif, menguntungkan dan melestarikan lahan.
\end{abstract}

\section{Kata kunci : Jagung, Tumpang Sari, Perkebunan}

\section{PENDAHULUAN}

Pertanian merupakan kegiatan pemanfaatan sumber daya hayati yang dilakukan manusia untuk menghasilkan bahan pangan, bahan baku industri, atau sumber energi serta untuk mengelola lingkungan hidup. Sektor perkebunan merupakan sektor yang memiliki peranan penting dalam menopang perekonomian Riau, Perkebunan kelapa sawit di Provinsi Riau pada Tahun 2015 mencapai 2,42 juta hektare, atau sekitar 25\% dari luas sawit secara nasional.

Provinsi Riau memiliki tanaman perkebunan kelapa sawit yang cukup luas, luasnya areal perkebunan memungkinkan untuk berbagi lahan dengan tanaman tumpang sari agar lahan terebut tidak sia-sia karena hanya ditumbuhi gulma. Penanaman dengan sistem tumpang sari yang umum dilakukan adalah penanaman dalam waktu yang hampir bersamaan untuk dua 
jenis tanaman yang sama seprti jagung dan kedelai, jagung dan kacang tanah. Namun penerapan sistem tumpang sari pada tanaman monokultur seperti sawit dapat dilakukan pada saat tanaman pokok masih kecil atau belum produktif.

Tanaman tumpang sari memiliki banyak manfaat seperti menghambat pertumbuhan rumput liar dan menambah pendapatan para petani.

\section{TINJAUAN PUSTAKA}

Kelapa sawit dapat tumbuh baik pada sejumlah besar jenis tanah di wilayah tropika. Persyaratan mengenai jenis tanah tidak terlalu spesifik seperti persyaratan faktor iklim. Hal yang perlu ditekankan adalah pentingnya jenis tanah untuk menjamin ketersediaan air dan ketersediaan bahan organik dalam jumlah besar yang berkaitan dengan jaminan ketersediaan air (Mangoensoekarjo, 2005).

Jenis tanah di Riau didominasi oleh Podsolik Merah Kuning (PMK) yang dikenal mengandung sedikit unsur hara, sedikit mengandung bahan organik, dan $\mathrm{pH}$ yang rendah (Surtinah, et al., 2012). Potensi tanah podzolik merah kuning untuk tanaman perkebunan seperti Sawit, Karet, dan Hutan tanaman industri terbukti mampu meningkatkan produktivitas tanaman yang baik, namun untuk tanaman pangan seperti Jagung memerlukan penanganan yang khusus (Prasetyo, 2006).

Menurut (W, 1983) sistem tanam ganda dibedakan menjadi 3 tipe pokok yaitu :

1. Pola tanam tumpang sari (Inter cropping) adalah menanam dua atau lebih jenis tanaman pokok dan tanaman yang lain sebagai tanaman tambahan atau tanaman sela.

2. Pola tanam bergilir (Sequential cropping) adalah menanam dua atau lebih jenis tanaman secara bergilir pada waktu tertentu, jenis tanaman kedua ditanam sesudah tanaman yang pertama dipanen.

3. Pola tanam sela adalah suatu bentuk pola tanam polykultur (campuran) yang dilakukan antara jenis tanaman semusim dengan tanaman tahunan. Sistem ini biasanya dilakukan pada tanaman perkebunan atau tanaman kehutanan, misalnya perkebunan kelapa sawit, karet atau jati. Pada sistem ini tanaman semusim ditanam sewaktu tanaman tahunan masih kecil dan belum produktif.

Tumpang sari ditujukan untuk memanfaatkan lingkungan (hara, air dan sinar matahari) sebaik-baiknya agar diperoleh produksi maksimal. 
Pertanaman jagung yang luas adalah pada dearah-daerah beriklim sedang dimana jagung ditanam pada waktu-waktu musim panas dimana matahari dan air optimal untuk pertumbuhannya. Pada umumnya jagung dapat ditanam disemua belahan bumi kecuali pada daerah yang terlalu dingin atau daerah yang musim pertumbuhannya terlalu singkat. Jagung merupakan tanaman yang menghendaki keadaan cuaca yang cukup panas bagi pertumbuhannya, dimana tanaman jagung memerlukan panas dan lembab dari waktu tanam sampai pada priode mengakhiri pembuahan (Effendi, et al., 1991). Umur panen 70 hari setelah tanam menunjukkan kadar gula biji jagung manis yang paling tinggi yaitu $15.78 \%$ untuk varietas sweet Boy (Surtinah, 2008), apabila jagung manis dipanen pada waktu yang tidak tepat akan berpengaruh terhadap kadar gula biji.

Penerapan pola penanaman sistem tumpangsari sangat dipengaruhi oleh pengaturan jarak tanam (densitas) dan pemilihan varietas. Pengaturan jarak tanam merupakan faktor-faktor yang dibutuhkan tanaman dapat tersedia bagi setiap tanaman dan mengoptimalisasi penggunaan faktor ligkungan yang tersedia (Sitompul, 1995).

\section{HASIL DAN PEMBAHASAN}

Secara umum kondisi perkebunan kelapa sawit rakyat di Provinsi Riau dapat dikelompokkan dalam tiga status tanaman. Pertama, kebun kelapa sawit rakyat dalam kondisi Tanaman Belum Menghasilkan, kedua dalam kondisi Tanaman Menghasilkan, dan ketiga dalam kondisi Tanaman Tua Rusak (TTR).

Tujuan pemeliharaan tanaman belum menghasilkan diantaranya agar tanaman tumbuh cepat, sehat dan dapat memasuki periode tanman menghasilkan (TM) lebih awal dengan biaya pemeliharaan yang rasional. Pemeliharaan TBM meliputi konsolidasi/penyisipan, mengendalikan hama dan penyakit, menyiang, memupuk, merawat jalan, jembatan dan system drainase. Pada saat peremajaan terdapat potensi penggunaan lahan yang dapat dimanfaatannya untuk pengembangan tanaman tumpangsari pangan (jagung) sebagai pengganti tanaman penutup tanah.

Tanaman sela yang dipilih harus memiliki fungsi saling melengkapi sehingga tanaman dapat berinteraksi dengan baik dan tidak bersaing satu sama lain, ini perlu diperhatikan karena akan 
mempengaruhi pertumbuhan tanaman utama, pelestarian tanah dan pengendalian hama yang pada akhirnya akan meningkatkan hasil dan pendapatan petani.

Analisis usahatani (B/C ratio) polatanam kelapa (Lolitsela, 2003)

\begin{tabular}{|r|l|c|}
\hline No. & \multicolumn{1}{|c|}{ Model pola tanam } & B/C ratio \\
\hline 1. & Kelapa + Jagung Hibrida & 2,98 \\
\hline 2. & Kelapa + Kacang Tanah & 1,87 \\
\hline 3. & Kelapa + Kedelai & 1,29 \\
\hline 4. & Kelapa + Jahe Gajah & 2,17 \\
\hline 5. & Kelapa + Kunyit & 2,55 \\
\hline 6. & Kelapa + Kencur & 1,97 \\
\hline 7. & Kelapa + Temulawak & 1,63 \\
\hline
\end{tabular}

Sumber (W, 2003).

Tabel diatas menunjukkan hasil analisis usahatani pola tanam kelapa, namaun anatara kelapa dan kelapa sawit, kedua jenis tanaman ini mempunyai sifat agronomis dan agroekologis yang tidak jauh berbeda sehingga teknologi tanaman sela yang telah diperoleh dari salah satu jenis tanaman berpeluang diterapkan pada jenis lainnya. Berdasarkan tabel diatas pola tanaman tumpang sela antara kelapa sawit dan jangung menambah keuntungan petani B/C ratio 2,98. Keuntungan lainnya adalah menunjang keberlanjutan usaha pertanian melalui maksimalisasi penggunaan lahan, stabilitas hasil dan keuntungan.

\section{KESIMPULAN}

Penanaman sela pada perkebunan kelapa sawit memiliki beberapa manfaat yaitu sebagai pelestarian/maksimalisasi sumber tanah, pengendalian hama, serta sebagai sumber penambahan pendapatan petani. 


\section{Daftar pustaka}

Effendi S and Sulistiati N Bercocok Tanam Jagung [Book]. - Jakarta : Yasaguna, 1991.

Mangoensoekarjo S. H. Semagun Manajemen Agribisnis Kelapa Sawit [Journal]. - Yogyakarta :

Gadjah Mada University Press, 2005.

Prasetyo B.H. dan D.A Suriadikarta Karakteristik, Potensi, dan Teknologi Pengolahan Tanah Ultisol untuk Pengembangan Pertanian Lahan Kering di Indonesia [Journal] // Jurnal Litbang Pertanian. 2006. - Vol. 25(2). - pp. 39-46.

Sitompul S. M. \& B. Guritno Analisis Pertumbuhan Tanaman [Journal]. - Yogyakarta : Gadjah Mada University Press, 1995.

Surtinah and Lidar S Pertumbuhan Vegetatif dan Kadar Gula Biji Jagung Manis (Zea mays saccharata, Sturt) di Pekanbaru. [Journal] // Jurnal Ilmiah Pertanian. - 2012. - Vol. 13(2). - pp. 73-78.

Surtinah Menentukan Umur Panen yang Tepat dengan Menguji Kadar Gula Jagung Manis [Journal] // Jurnal Ilmu Pertanian. - 2008. - Vol. 4(2). - pp. 15-21.

W Mangoendidjojo Selection in Intercropping with Spring Wheat (Triticium aestivum L.) and with Dry Beans (Phaeseolus vulgaris L.) [Journal]. - 1983. 